\title{
Effects of Primary Care Team Social Networks on Quality of Care and Costs for Patients With Cardiovascular Disease
}

\author{
Marlon P. Mundt, PbD \\ Valerie J. Gilchrist, $M D^{1}$ \\ Michael F. Fleming, $M D, M P H^{2}$ \\ Larissa I. Zakletskaia, $M A^{1}$ \\ Wen-Jan Tuan, MS, MPH' \\ Jobn W. Beasley, MD \\ 'Department of Family Medicine, Univer- \\ sity of Wisconsin School of Medicine and \\ Public Health, Madison, Wisconsin \\ ${ }^{2}$ Departments of Psychiatry and Family \\ Medicine, Northwestern University Fein- \\ berg School of Medicine, Chicago, Illinois
}

\begin{abstract}
PURPOSE Cardiovascular disease is the leading cause of mortality and morbidity in the United States. Primary care teams can be best suited to improve quality of care and lower costs for patients with cardiovascular disease. This study evaluates the associations between primary care team communication, interaction, and coordination (ie, social networks); quality of care; and costs for patients with cardiovascular disease.
\end{abstract}

METHODS Using a sociometric survey, 155 health professionals from 31 teams at 6 primary care clinics identified with whom they interact daily about patient care. Social network analysis calculated variables of density and centralization representing team interaction structures. Three-level hierarchical modeling evaluated the link between team network density, centralization, and number of patients with a diagnosis of cardiovascular disease for controlled blood pressure and cholesterol, counts of urgent care visits, emergency department visits, hospital days, and medical care costs in the previous 12 months.

RESULTS Teams with dense interactions among all team members were associated with fewer hospital days (rate ratio $[\mathrm{RR}]=0.62 ; 95 \% \mathrm{Cl}, 0.50-0.77$ ) and lower medical care costs $(-\$ 556 ; 95 \% \mathrm{Cl},-\$ 781$ to $-\$ 331)$ for patients with cardiovascular disease. Conversely, teams with interactions revolving around a few central individuals were associated with increased hospital days ( $R R=1.45 ; 95 \%$ $\mathrm{Cl}, 1.09-1.94)$ and greater costs $(\$ 506 ; 95 \% \mathrm{Cl}, \$ 202-\$ 810)$. Team-shared vision about goals and expectations mediated the relationship between social network structures and patient quality of care outcomes.

CONCLUSIONS Primary care teams that are more interconnected and less centralized and that have a shared team vision are better positioned to deliver highquality cardiovascular disease care at a lower cost.

Ann Fam Med 2015;13:139-148. doi: 10.1370/afm.1754.

\section{INTRODUCTION}

$\mathrm{P}$ roviding evidence-based high-quality care for patients with cardiovascular disease, the leading cause of morbidity and mortality, is a pervasive public health challenge. In the United States, cardiovascular disease was responsible for $32.8 \%$ of deaths and accounted for nearly $\$ 300$ billion in health care costs in $2008 .{ }^{1}$

To raise the level of health care quality, the Institute of Medicine recommends establishing a learning health care team "that continuously improves, by capturing and broadly disseminating lessons learned from every health care experience" while fostering "teamwork, staff empowerment, and open communication." ${ }^{2,3}$ High-functioning primary care teams have higher patient satisfaction, higher job satisfaction, and lower staff burnout, which are associated with higher quality of care. ${ }^{4-12}$

Primary care teams offer a unique opportunity to improve quality of care and lower medical costs for patients with cardiovascular disease. Through interdependent activities, team members provide support and share respon- 
sibilities for patient care (eg, adherence support, selfmanagement support, patient follow-up, medication management). Notably, team-based hypertension management interventions have shown the largest effects in blood pressure reduction in contrast with other tested interventions, such as patient education, clinician education, promotion of self-management, facilitated relay of clinical data, and financial incentives. ${ }^{13,14}$ On the basis of strong evidence of effectiveness, the Community Preventive Services Task Force recommends team-based care to improve blood pressure control. ${ }^{15-18}$

Unfortunately, limited evidence is available on how a team's interactions, communication, and coordination (ie, social networks) contribute to higher quality care at lower cost for patients with cardiovascular disease. A primary care team's relationships could be as fundamental to the team's delivery of high-quality care at lower cost as its reliance on medical technology, informational technology, and other infrastructural components..$^{8,19,20}$

Our study investigated which aspects of primary care team social networks are associated with higher quality of care and lower cost for patients with cardiovascular disease. For the purpose of this study, social networks are defined as "the pattern of friendship, advice, communication and support that exists among members of a social system" ${ }^{\prime 21}$ (ie, team members).

\section{METHODS}

\section{Data Source and Study Procedures}

The study data came from a selected sample of 6 primary care clinics caring for a wide range of the patient population across southern Wisconsin. Two of the clinics were urban, 3 were suburban, and 1 was rural. The clinics had from 3 to 11 primary care practitioners. On average, about $65 \%$ of the clinic population had health insurance through a commercial health plan. Medicare coverage varied by clinic from $6 \%$ to $19 \%$ of patients, and $5 \%$ to $6 \%$ of the population was covered by Medicaid. The Institutional Review Board of the University of Wisconsin approved the study.

All clinicians and staff were invited to schedule a 30-minute face-to-face structured interview that examined social network connections in teams and team climate. Eligibility criteria included age of 18 years or older, ability to read and understand English, and employment at the study site in a patient care or patient interaction role. Participants were asked to consider a team definition and indicate on a staff roster who was on their care team. The care team was defined as "the smallest unit of individuals within the clinic that care for a specific patient panel." For the analysis, care team membership included a lead physician, nurse practitioner or physician assistant, and all clinic employees who indicated on the roster that they belonged to that lead practitioner's care team. Clinic staff members could belong to more than 1 care team based on the responses to the team membership question. As an example, a registered nurse, medical assistant, laboratory technician, or medical receptionist could indicate belonging to the care teams of more than 1 practitioner-led team, thereby overlapping care team membership.

Using the clinic staff roster as an aid for memory recall, participants were then asked to identify with whom and how frequently they interacted face to face and via electronic health records (EHRs) in the clinic. These responses were used to calculate the presence or absence of social network ties between study team members. A connection between 2 team members was coded as present if the frequency of communication was reported as daily or multiple times each day. Communication ties to members outside the care team were not included in the calculations of team communication network variables for these analyses.

\section{Primary Care Team Measures}

\section{Team Social Network Variables}

The investigation relied on social network analysis, a mathematical evaluation of the human relationships in a social network, ${ }^{22}$ to quantify team social network effects on quality of care for patients with cardiovascular disease. Several social network analysis variables (density, centralization) were hypothesized to be related to patient outcomes.

Density is calculated as the percentage of network ties divided by the total possible number of network ties. Density provides a measure of the overall connectedness within the care team. In a dense network, information can flow quickly between team members, and social processes may result in positive intentions to use new information in daily practice.

Network centralization is a measure of the extent to which the interactions are organized around a single or small group of individuals. Centralization is calculated as the sum of the differences in in-degree nominations between the highest in-degree node in the network and all other nodes, divided by the largest sum of differences possible in any network of the same size. ${ }^{23}$ In-degree measures the connectedness of the individual to his or her team and is rated by the collective perspective of the team as opposed to a single person's perception. Centralized networks have the advantage of being able to disseminate information quickly and efficiently, but a highly centralized network may also concentrate power among a few individuals, resulting in less shared vision, decision making, and commitment to team goals. 


\section{Team Climate}

Team climate was measured with the 14 -item validated

Team Climate Inventory (TCI-14), using 5-point Likert scales. ${ }^{24}$ The TCI-14 measures teamwork in 4 sub-

scales: (1) focusing on clear and realistic goals (shared vision), (2) team member interactions that are participatory and interpersonally nonthreatening (psychological safety), (3) high standards of performance and appraisal of weaknesses (task orientation), and (4) support for innovation attempts (innovation support). For each TCI-14 subscale, items were coded from 1 to 5 , with higher scores indicating better team climate, and summed to produce individual subscale scores, which were later averaged across team members.

\section{Demographic Characteristics of Team Members} Health professionals reported their sex, job title, percentage of full-time employment, and years working at the clinic. Staff turnover was aggregated to the team level as a percentage of team members who had worked in the clinic for 1 year or less.

\section{Patient Panels}

Patient outcome data for team panels of patients with cardiovascular disease were extracted from a common EHR system. To ensure continuity of care, the teams' patient panels consisted of patients who had at least 1 visit with the lead clinician in the previous 12 months, and at least 2 visits in the previous 36 months. Cardiovascular disease diagnoses were determined by the presence of 2 validated International Classification of Diseases, Nintb Revision (ICD-9) codes for hypertension, congestive heart failure, coronary artery disease, heart attack, arrhythmia, cerebrovascular disease, or stroke (4010-4019, 42800-42802, 41401, 4300-4389, 4109, 42789) on 2 separate occasions within the previous 3 years. The sample size was 7,457 patients with a cardiovascular disease diagnosis.

\section{Quality of Care Outcome Measures}

Biometric Measures of Cholesterol and Blood Pressure In the EHR, any measurement of low-density lipoprotein (LDL) cholesterol of $<100 \mathrm{mg} / \mathrm{dL}$ or blood pressure $<130 / 80 \mathrm{~mm} \mathrm{Hg}$ in the previous 12 months was considered a positive indicator of effective control of cholesterol and blood pressure, respectively.

\section{Health Utilization Counts}

Number of urgent care visits, emergency department visits, and hospital visit days were extracted from EHRs as health care use counts for the previous 12 months.

\section{Medical Costs}

Costs of care were calculated by applying average medical expenses derived from published reports to health care use counts. ${ }^{25-27}$ An average 2013 cost of $\$ 266$ per urgent care visit, $\$ 664$ per emergency department visit, and $\$ 1,628$ per hospital day was applied to each patient record.

\section{Patient-Level Characteristics}

Patient-level control variables included sex, age, race/ ethnicity, insurance, and comorbidity. The Charlson comorbidity index ${ }^{28}(\mathrm{CCI})$ was calculated to account for illness severity.

\section{Statistical Analysis}

Patient panel outcome data were structured as patients nested under primary care teams nested within clinics. Three-level hierarchical analysis allowed testing for significant team-level effects while controlling for patient-level covariates and clinic-level clustering.

Multivariate analyses applied generalized linear mixed models ${ }^{29}$ (GLMMs) to test the association between team-level social network characteristics (density, centralization) and patient-level biometric cardiovascular disease outcomes, urgent care visits, emergency department visits, hospital visit days, and medical costs. To account for nonnormally distributed data, the 3-level GLMMs used a logit link function for binary patient outcomes hemoglobin $\mathrm{A}_{1 \mathrm{c}}$ levels, (LDL cholesterol levels, blood pressure control) and a log link function with an overdispersion parameter for count outcomes (urgent care visits, emergency department visits, hospital days). ${ }^{30}$ We used a normal link function for medical costs. First, a 2-level reduced-form GLMM examined associations between team social network (ie, face-to-face and/or EHR communication ties) variables and patient-level outcomes without adjusting for patient covariates or clinic-level effects. Second, a full 3-level model added patientlevel covariates (age, race, sex, insurance, CCI) and clinic fixed effects to the reduced GLMM. Third, the analysis calculated face-to-face and EHR communication network variables separately, and included both predictors in the 3-level GLMM.

Finally, exploratory structural equation modeling ${ }^{31}$ tested the path from team face-to-face and EHR communication network variables to the team's patient panel outcomes as mediated by team climate (TCI-14) subscale measures and staff turnover. Team climate subscales, staff turnover, and patient outcomes were aggregated to the team level and tested sequentially in the structural equation models.

The analyses used UCINET 6 for constructing networks and obtaining structural equation modeling measurements, ${ }^{32}$ HLM 7.0 (Scientific Software International) for GLMM, and Mplus 7.11 (http://www.statmodel.com/ index.shtml) for structural equation modeling. 


\section{RESULTS}

A total of 160 health professionals at the 6 study clinics were invited to participate, and 155 (97\%) completed the face-to-face interviews between May 2013 and December 2013. All clinics had used the Epic Systems EHR since 2003. Thirty-one primary care teams cared for patients at the 6 primary care clinics. Median team size was 19 team members. On average, clinic members other than the primary care practitioner belonged to 4 practitioner-led primary care teams.

As displayed in Table 1, primary care team members included 20 physicians, 7 nurse practitioners or physician assistants, 30 registered nurses, 29 licensed practice nurses or medical assistants, 38 medical receptionists, and 23 laboratory or radiology technicians. That care team members were $94.8 \%$ female is in line with US Census Bureau data, which report that $91 \%$ of all nurses, nurse practitioners, and licensed practice nurses, as well as $97 \%$ of all medical receptionists, are women. ${ }^{33}$

Table 2 provides means and standard deviations for the calculated team social network variables, quality

\begin{tabular}{|c|c|c|c|}
\hline Characteristic & No. (\%) & Mean (SD) & Range $^{a}$ \\
\hline \multicolumn{4}{|l|}{ Sex } \\
\hline Male & $8(5.2)$ & $7.2(2.7)$ & $3-11$ \\
\hline Female & $147(94.8)$ & $10.8(4.0)$ & $2-25$ \\
\hline \multicolumn{4}{|l|}{ Position } \\
\hline Physician & $20(12.9)$ & $7.2(2.3)$ & $3-12$ \\
\hline NP/PA & $7(4.5)$ & $7.3(2.0)$ & $5-11$ \\
\hline Clinic manager & $6(3.9)$ & $10.8(2.8)$ & $8-15$ \\
\hline RN & $30(19.4)$ & $12.4(4.3)$ & $4-25$ \\
\hline LPN/MA & $29(18.7)$ & $13.0(2.7)$ & $9-19$ \\
\hline Medical receptionist & $38(24.5)$ & $11.8(3.0)$ & $5-17$ \\
\hline $\begin{array}{l}\text { Laboratory/radiology } \\
\text { technician }\end{array}$ & $23(14.8)$ & $8.2(4.4)$ & $2-18$ \\
\hline $\begin{array}{l}\text { Other (scribe/ } \\
\text { phlebotomist) }\end{array}$ & $2(1.2)$ & $4.5(0.7)$ & $4-5$ \\
\hline \multicolumn{4}{|l|}{ Years at clinic } \\
\hline$\leq 1$ & $30(19.4)$ & $10.1(4.2)$ & $2-15$ \\
\hline 1 to 3 & $43(27.7)$ & $12.4(4.4)$ & $4-25$ \\
\hline 3 to 6 & $29(18.7)$ & $9.4(3.5)$ & $2-18$ \\
\hline 6 to 10 & $16(10.3)$ & $11.1(3.6)$ & $4-1$ \\
\hline$>10$ & $37(23.9)$ & $9.5(3.1)$ & $4-15$ \\
\hline \multicolumn{4}{|l|}{ Full-time employment } \\
\hline$\leq 50 \%$ & $23(14.8)$ & $7.3(3.4)$ & $2-14$ \\
\hline$>50 \%$ to $75 \%$ & $28(18.1)$ & $9.2(3.5)$ & $4-17$ \\
\hline$>75 \%$ & $104(67.1)$ & $11.8(3.7)$ & $4-25$ \\
\hline
\end{tabular}

$\mathrm{LPN}=$ licensed practical nurse; $\mathrm{MA}=$ medical assistant; $\mathrm{NP}=$ nurse practitioner; $\mathrm{PA}=$ physician assistant; $\mathrm{RN}=$ registered nurse

Note: Count of incoming communication ties (ie, the number of other team members who report communicating with the individual about patient care on a daily basis).

ainimum-maximum. of care, and cost outcomes. The mean density of daily team interactions about patient care (ie, face-to-face or by EHR) was 0.53 . Mean daily face-to-face interaction density was 0.45 , which suggests that there were slightly fewer than one-half of all face-to-face connections possible. Density of EHR communication within the care team averaged 0.31. Overall, teams had higher centralization of connections in face-to-face interactions (mean $=0.28$ ) than in EHR communications (mean $=0.24$. As an illustration, Figure 1 shows a team with dense interactions and low centralization (Panel A) in contrast to a team with sparse interactions and high centralization (Panel B). Teams scored highest on the team-shared vision construct of the TCI-14, with the lowest TCI-14 subscale score being innovation. As seen in Table 2, on average $39 \%$ of patients with

Table 2. Primary Care Team Characteristics and Outcomes for Patients With Cardiovascular Disease

\begin{tabular}{|c|c|c|}
\hline Characteristic & $\begin{array}{c}\text { Value } \\
\text { Mean (SD) }\end{array}$ & Range $^{a}$ \\
\hline \multicolumn{3}{|l|}{ Primary care teams $(n=31)$} \\
\hline \multicolumn{3}{|l|}{ Social networks variable } \\
\hline Team social network density & $0.53(0.12)$ & $0.36-0.77$ \\
\hline $\begin{array}{l}\text { Team social network } \\
\text { centralization }\end{array}$ & $0.29(0.10)$ & $0.13-0.43$ \\
\hline Face-to-face interaction density & $0.45(0.11)$ & $0.31-0.69$ \\
\hline $\begin{array}{l}\text { Face-to-face interaction } \\
\text { centralization }\end{array}$ & $0.28(0.08)$ & $0.15-0.41$ \\
\hline EHR communication density & $0.31(0.08)$ & $0.19-0.46$ \\
\hline $\begin{array}{l}\text { EHR communication } \\
\text { centralization }\end{array}$ & $0.24(0.07)$ & $0.11-0.43$ \\
\hline \multicolumn{3}{|l|}{ Team climate (TCI-14) score } \\
\hline Shared vision (scale: 0-16) & $12.8(0.4)$ & $11.6-13.6$ \\
\hline Psychological safety (scale: 0-16) & $11.4(1.1)$ & $8.6-12.3$ \\
\hline Task orientation (scale: $0-12)^{b}$ & $8.5(0.5)$ & $7.5-9.3$ \\
\hline Innovation support (scale: $0-12)^{b}$ & $7.9(0.6)$ & $6.3-8.8$ \\
\hline \multicolumn{3}{|l|}{ Team characteristics } \\
\hline Team size, No. & $22.2(7.5)$ & $12-28$ \\
\hline $\begin{array}{l}\text { Staff turnover in previous } \\
12 \mathrm{mo} \%\end{array}$ & 19 & $\ldots$ \\
\hline \multicolumn{3}{|l|}{$\begin{array}{l}\text { Patient panel outcomes in past } \\
12 \mathrm{mo}\end{array}$} \\
\hline \multicolumn{3}{|l|}{ Team patients $(\mathrm{n}=7,457)$} \\
\hline $\begin{array}{l}\text { With controlled LDL cholesterol } \\
(<100 \mathrm{mg} / \mathrm{dL}), \%\end{array}$ & 39 & $\ldots$ \\
\hline $\begin{array}{l}\text { With controlled blood pressure } \\
(<130 / 80 \mathrm{~mm} \mathrm{Hg}), \%\end{array}$ & 71 & $\cdots$ \\
\hline \multicolumn{3}{|l|}{$\begin{array}{l}\text { Health care use per patient in } \\
\text { patient panel }\end{array}$} \\
\hline Urgent care visits, No. & $0.10(0.44)$ & $\cdots$ \\
\hline Emergency department visits, No. & $0.24(1.20)$ & $\ldots$ \\
\hline Hospital days, No. & $0.65(4.44)$ & $\ldots$ \\
\hline Medical costs, US\$ & $1,241(7,538)$ & $\ldots$ \\
\hline
\end{tabular}


cardiovascular disease had cholesterol levels controlled and $71 \%$ had blood pressure controlled. There were 739 urgent care visits, 1,802 emergency department visits, and 4,835 hospital days observed in the EHR.

The models in Table 3 provide both the unadjusted reduced-form GLMM and adjusted full GLMM associations between social network (ie, face-to-face and
EHR daily team interactions) variables of density and centralization and quality of care measures. First, the reduced GLMM, unadjusted for patient and clinic confounding, shows that team social network density (ie, more connections) was associated with significantly fewer urgent care visits (rate ratio $[R R]=0.28, P<.001$ ), emergency department visits $(\mathrm{RR}=0.58, P<.01)$, and

\section{Figure 1. Primary care team communication networks about patient care.}

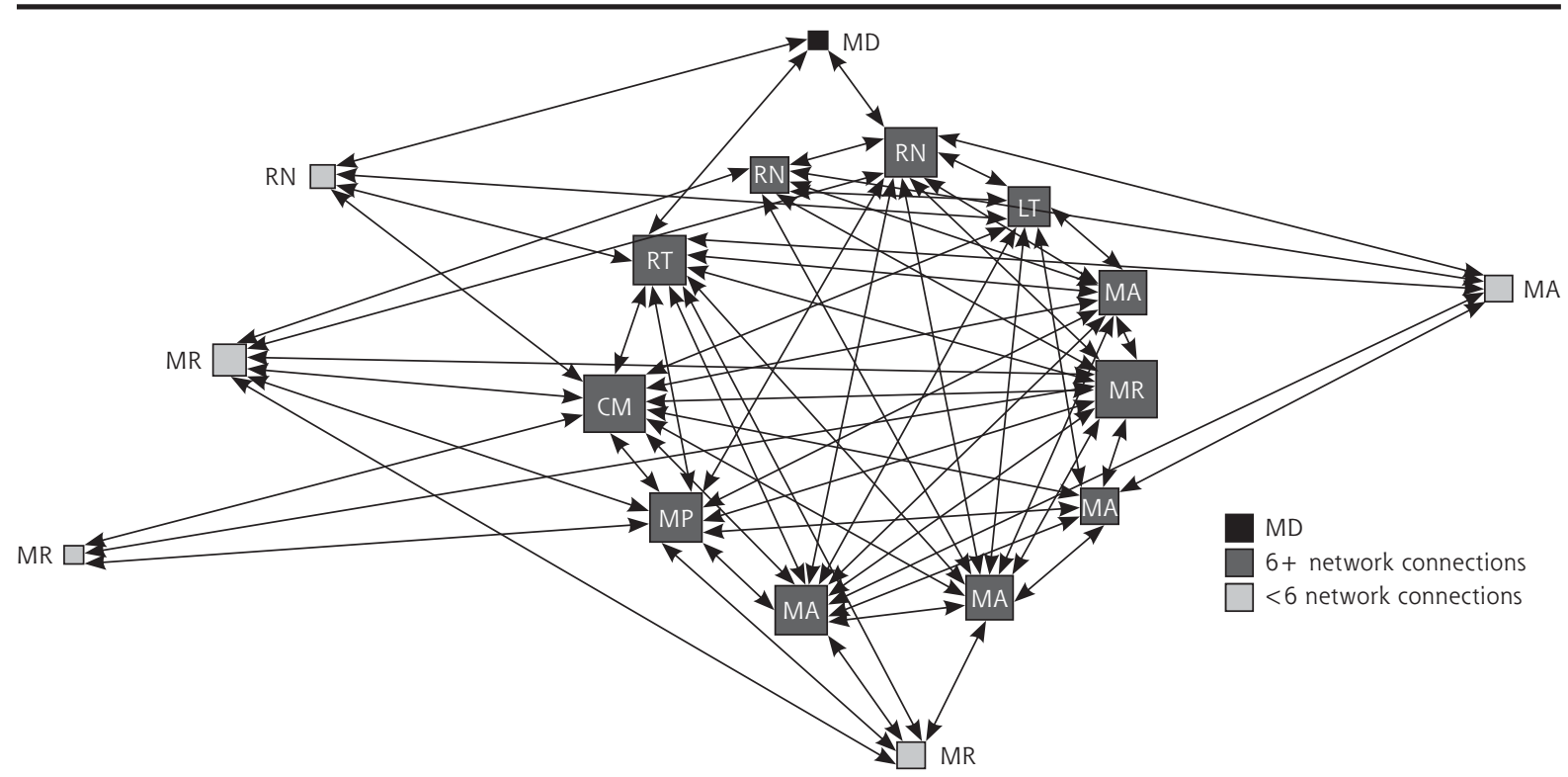

A. Densely interconnected team (density $=0.64$, centralization $=0.19$ ).

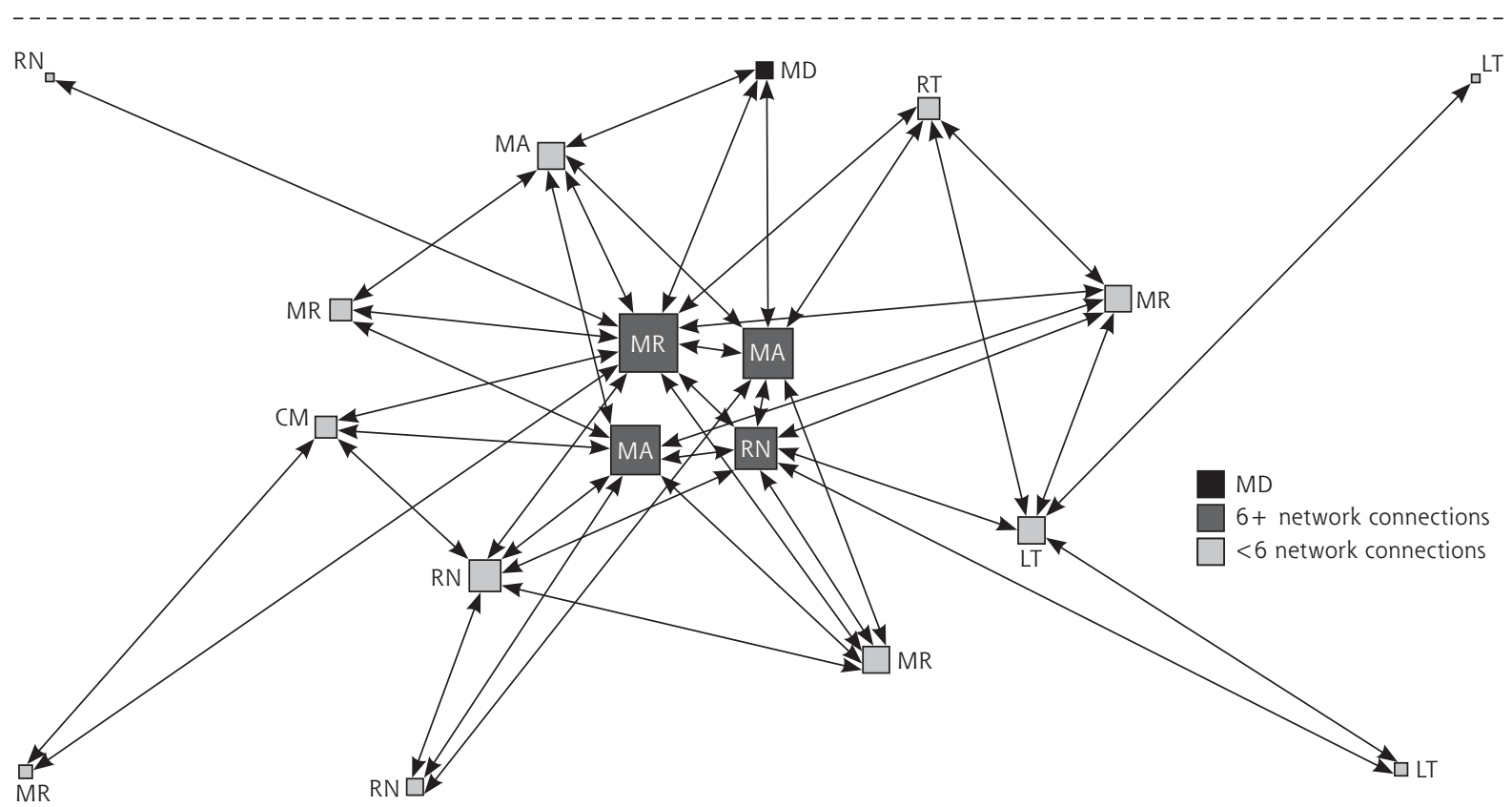

B. Highly centralized team (density $=0.44$, centralization $=0.38$ ).

$\mathrm{CM}=$ clinic manager; $\mathrm{LT}=$ laboratory technician; $\mathrm{MA}=$ medical assistant; $\mathrm{MD}=$ physician; $\mathrm{MR}=$ medical receptionist; $\mathrm{RN}=$ registered nurse; $\mathrm{RT}=$ radiology technician. Note: Symbol size proportional to number of connections. 
Table 3. Hierarchical Modeling of the Association Between Team Social Networks and Outcomes for Panel of Patients With Cardiovascular Disease

\begin{tabular}{|c|c|c|c|c|c|c|}
\hline Variable & $\begin{array}{l}\text { BP Control } \\
\text { OR }(95 \% \mathrm{CI})\end{array}$ & $\begin{array}{l}\text { LDL Cholesterol } \\
\text { Control } \\
\text { OR }(95 \% \mathrm{Cl})\end{array}$ & $\begin{array}{c}\text { UC Visits } \\
\text { RR (95\% CI) }\end{array}$ & $\begin{array}{c}\text { ED Visits } \\
\text { RR (95\% CI) }\end{array}$ & $\begin{array}{l}\text { Hospital Days } \\
\text { RR (95\% CI) }\end{array}$ & $\begin{array}{c}\text { Cost (\$) } \\
\beta \text { (SE) }\end{array}$ \\
\hline \multicolumn{7}{|l|}{ Reduced form model } \\
\hline $\begin{array}{l}\text { Team social network } \\
\text { density }\end{array}$ & $1.14(0.98-1.33)$ & $1.13(0.97-1.31)$ & $0.28^{b}(0.19-0.40)$ & $0.58^{c}(0.42-0.80)$ & $0.64^{b}(0.51-0.80)$ & $-516^{b}(129)$ \\
\hline $\begin{array}{l}\text { Team social network } \\
\text { centralization }{ }^{a}\end{array}$ & $1.00(0.84-1.19)$ & $0.94(0.80-1.11)$ & $3.07^{b}(2.09-4.51)$ & $1.70^{c}(1.23-2.35)$ & $1.47^{c}(1.14-1.89)$ & $519^{c}(143)$ \\
\hline \multicolumn{7}{|l|}{ Full model ${ }^{d}$} \\
\hline $\begin{array}{l}\text { Team social network } \\
\text { density }\end{array}$ & $1.15(0.99-1.34)$ & $1.14(1.00-1.31)$ & $0.95(0.55-1.66)$ & $0.98(0.50-1.89)$ & $0.62^{b}(0.50-0.77)$ & $-556^{\mathrm{b}}(115)$ \\
\hline $\begin{array}{l}\text { Team social network } \\
\text { centralization }^{a}\end{array}$ & $1.03(0.85-1.25)$ & $0.93(0.79-1.08)$ & $1.20(0.79-1.81)$ & $1.33(0.83-2.13)$ & $1.45^{c}(1.09-1.94)$ & $506^{c}(155)$ \\
\hline \multicolumn{7}{|c|}{$\mathrm{BP}=$ blood pressure; $\mathrm{ED}=$ emergency department; $\mathrm{LDL}=$ low-density lipoprotein; $\mathrm{OR}=$ odds ratio; $\mathrm{RR}=$ rate ratio; $\mathrm{SE}=$ standard error; $\mathrm{UC}=$ urgent care. } \\
\hline \multicolumn{7}{|c|}{$\begin{array}{l}\text { a Team social network interaction related to daily face-to-face and/or EHR communication connections about patient care in a team. } \\
\text { b } P<.001 \text {. } \\
\text { c } P<.01 \text {. }\end{array}$} \\
\hline
\end{tabular}

hospital days $(\mathrm{RR}=0.64, P<.001)$, and with a $\$ 516$ reduction in medical costs per patient in the past 12 months. On the other hand, more team social network centralization (ie, most connections around a few people) was associated with greater numbers of urgent care visits $(\mathrm{RR}=3.07, P<.001)$, emergency department visits $(\mathrm{RR}=1.70, P<.01)$, and hospital days $(\mathrm{RR}=1.47$, $P<.01)$ and increased costs of $\$ 519$ per patient with cardiovascular disease.

Second, the full GLMM, after adjusting for patientlevel covariates and clinic-level clustering, shows that there was still a significant association between team social network density and reduced hospital days ( $R R=0.62, P<.001)$, as well as a significant reduction in medical costs by an average of $\$ 556$ (95\% CI, $-\$ 781$ to $-\$ 331)$ per patient. In contrast, network centralization was associated with more hospital days $(\mathrm{RR}=1.45$ $P<.01)$ and $\$ 506(95 \% \mathrm{CI}, \$ 202-\$ 810)$ in higher medical costs per patient.

Table 4 provides full GLMM results that evaluate the association between face-to-face and EHR communication and quality of care measures. An increase of 1 $\mathrm{SD}$ in face-to-face interaction density within the team, after adjusting for patient-level covariates, EHR communication, and clinic-level fixed effects, was associated with a $17 \%$ (adjusted odds ratio $[\mathrm{OR}]=1.17 ; 95 \% \mathrm{CI}$, 1.00-1.37) greater odds of a patient with cardiovascular disease having effectively controlled LDL cholesterol levels. Interestingly, higher density of EHR communication within the team was associated with $15 \%$ (adjusted $\mathrm{OR}=0.85 ; 95 \% \mathrm{CI}, 0.72-1.00$ ) lower odds of a patient with cardiovascular disease having effectively controlled LDL cholesterol levels.
Furthermore, face-to-face interaction density was associated with a significant reduction in health care use. An increase in $1 \mathrm{SD}$ in density of team face-toface interaction was correlated with: $66 \%$ fewer urgent care visits (adjusted $\mathrm{RR}=0.34$; 95\% CI, 0.12-0.98), 72\% fewer emergency department visits (adjusted $\mathrm{RR}=0.28$; 95\% CI 0.12-0.63), and 37\% fewer hospital days (adjusted RR $=0.63 ; 95 \% \mathrm{CI}, 0.40-1.00$ ) in the team's panel of patients with cardiovascular disease. Notably, more density in team EHR communication was correlated with a $134 \%$ increase (adjusted $\mathrm{RR}=2.34,95 \%$ CI, 1.10-4.97) in the rate of emergency department use for the team's patients.

In addition, denser face-to-face interaction networks in teams were associated with lower overall health care costs for patients with cardiovascular disease than for patients of teams with sparser face-toface interactions. Each 1 SD increase in face-to-face interaction density within the team was associated with \$594 (95\% CI, \$141-\$1,195) lower health care costs per patient in the previous 12 months.

Finally, Figure 2 displays structural equation modeling of the mediating effects of team climate on team social networks and quality of cardiovascular disease care. Team shared vision, derived from the TCI-14, significantly mediated the association between faceto-face interaction density in primary care teams and reduced urgent care visits, emergency department visits, and hospital days for patients. As seen in Figure 2 , for every $1 \mathrm{SD}$ increase in face-to-face interaction density, there was a 0.82 SD increase in team shared vision; and for every $1 \mathrm{SD}$ increase in team shared vision, there were corresponding $0.69,0.51$, and 
Table 4. Three-Level Hierarchical Model of the Association Between Face-to-Face and EHR Communication Networks and Outcomes for Patients With Cardiovascular Disease $(n=31$ teams, $n=7,457$ patients)

\begin{tabular}{|c|c|c|c|c|c|c|}
\hline Variable & $\begin{array}{l}\text { BP Control } \\
\text { Adj OR } \\
(95 \% \mathrm{Cl})\end{array}$ & $\begin{array}{l}\text { LDL Cholesterol } \\
\text { Control } \\
\text { Adj OR }(95 \% \mathrm{Cl})\end{array}$ & $\begin{array}{l}\text { UC Visits } \\
\text { Adj RR } \\
(95 \% \mathrm{CI})\end{array}$ & $\begin{array}{l}\text { ED Visits } \\
\text { Adj RR } \\
(95 \% \mathrm{Cl})\end{array}$ & $\begin{array}{l}\text { Hospital Days } \\
\text { Adj RR } \\
(95 \% \mathrm{CI})\end{array}$ & $\begin{array}{l}\text { Cost (US\$) } \\
\text { Adj } \beta \text { (SE) }\end{array}$ \\
\hline \multicolumn{7}{|l|}{$\begin{array}{l}\text { Primary care team } \\
\text { social networks }\end{array}$} \\
\hline $\begin{array}{l}\text { Face-to-face inter- } \\
\text { action density }\end{array}$ & $1.19(0.89-1.59)$ & $1.17^{\mathrm{a}}(1.00-1.37)$ & $0.34^{a}(0.12-0.98)$ & $0.28^{b}(0.12-0.63)$ & $0.63(0.40-1.00)$ & $-594^{a}(240)$ \\
\hline \multicolumn{7}{|l|}{ Patient characteristics } \\
\hline Male & $1.52^{c}(1.23-1.87)$ & $1.67^{c}(1.51-1.88)$ & $0.79^{b}(0.67-0.93)$ & $0.94(0.85-1.04)$ & $0.97(0.91-1.03)$ & $118(180)$ \\
\hline Age & $0.99^{b}(0.99-1.00)$ & $1.01^{c}(1.01-1.02)$ & $0.96^{c}(0.95-0.97)$ & $0.98^{c}(0.97-0.99)$ & $0.99(0.98-1.00)$ & $-24^{b}(8)$ \\
\hline Age-squared $(\div 10)$ & $1.00(0.99-1.01)$ & $0.97^{c}(0.96-0.98)$ & $1.00(0.99-1.01)$ & $1.01^{c}(1.00-1.01)$ & $1.00(0.99-1.01)$ & $-1(3)$ \\
\hline White Hispanic & $2.01(0.97-4.18)$ & $1.48(0.91-2.39)$ & $1.16(0.78-1.73)$ & $1.17(0.87-1.57)$ & $0.50^{c}(0.34-0.74)$ & $-453(828)$ \\
\hline Black & $0.72(0.49-1.07)$ & $0.86(0.56-1.32)$ & $1.79^{a}(1.05-3.06)$ & $1.89^{a}(1.03-3.47)$ & $0.80(0.32-2.00)$ & $-160(705)$ \\
\hline Private insurance & $4.71^{c}(2.44-9.12)$ & $1.69^{c}(1.36-2.10)$ & $1.88^{\mathrm{b}}(1.27-2.79)$ & $0.71^{c}(0.59-0.85)$ & $0.46^{c}(0.42-0.51)$ & $-1,135^{b}(359)$ \\
\hline Medicaid & $2.64^{\mathrm{a}}(1.04-6.73)$ & $1.40(0.98-1.99)$ & $3.18^{c}(2.03-4.97)$ & $1.45^{\mathrm{b}}(1.15-1.84)$ & $0.81^{\mathrm{a}}(0.69-0.95)$ & $-588(581)$ \\
\hline Medicare & $3.65^{c}(1.90-7.04)$ & $2.24^{c}(1.81-2.79)$ & $1.52^{\mathrm{a}}(1.01-2.29)$ & $1.51^{\mathrm{c}}(1.28-1.78)$ & $0.84^{c}(0.77-0.91)$ & $-817^{a}(364)$ \\
\hline $\begin{array}{l}\text { Charlson comor- } \\
\text { bidity index }\end{array}$ & $1.4^{c}(1.09-1.20)$ & $1.23^{c}(1.20-1.26)$ & $1.06^{b}(1.02-1.10)$ & $1.32^{c}(1.29-1.34)$ & $1.36^{c}(1.34-1.37)$ & $690^{c}(47)$ \\
\hline \multicolumn{7}{|c|}{$\begin{array}{l}\text { Adj } \mathrm{OR}=\text { adjusted odds ratio; } \mathrm{Adj} \mathrm{RR}=\text { adjusted rate ratio; } \mathrm{Adj} \beta=\text { adjusted regression coefficient; } \mathrm{BP}=\text { blood pressure; } \mathrm{ED}=\text { emergency department; } \mathrm{EHR}=\text { electronic } \\
\text { health record; } \mathrm{LDL}=\text { low-density lipoprotein; } \mathrm{SE}=\text { standard error; } \mathrm{UC}=\text { urgent care. }\end{array}$} \\
\hline \multicolumn{7}{|c|}{ Notes: Confidence intervals rounded to 2 significant digits. Statistically significant intervals for OR and RR do not contain 1.} \\
\hline $\begin{array}{l}\text { a } P<.05 \\
\text { b } P<.01 \\
\text { c } P<.001\end{array}$ & & & & & & \\
\hline
\end{tabular}

0.47 SD decreases in urgent care visits, emergency department visits, and hospital days, respectively. Aggregating these 2 sequential effects, for every $1 \mathrm{SD}$ increase in face-to-face interaction density, there was a corresponding $0.56,0.42$, and $0.38 \mathrm{SD}$ decrease in urgent care visits, emergency care visits, and hospital days, respectively. Staff turnover and the other TCI-14 subscales (psychological safety, task orientation, and innovation support) were not significant mediators in the structural equation model.

\section{Sensitivity Analyses}

We conducted a series of sensitivity analyses to test the assumptions that the models had fully controlled for patient severity and that additional team characteristics did not confound the relationship between team social network structures and quality of care outcomes for patients with cardiovascular disease. These models added last blood pressure measurement, last LDL cholesterol reading, and last creatinine blood test for kidney function, as well as team size, the percentage of part-time team members, the average number of years team members worked at the clinic, and the ratio of registered nurses to other staff members in the team as potential confounders. The main study results did not change after the addition of these variables to the model. Full results are available upon request.

\section{DISCUSSION}

This study evaluated which primary care team social network structures were associated with higher quality of care for patients with cardiovascular disease. Overall, the results show that teams with higher density of daily interactions (face to face or by EHR) among all team members and lower centralization were associated with better quality of care. Specifically, teams with more members reporting daily interactions with a greater number of team members show better quality of care, as measured by a $38 \%$ reduction in hospital days and $\$ 516$ less spent on average per patient in the previous 12 months.

Furthermore, our results suggest that teams with more daily face-to-face interactions had a $66 \%$ reduction in urgent care visits, a $73 \%$ reduction in emergency department visits, and \$594 less spent in medical costs per patient in the previous 12 months. Keeping in mind that all participating clinics had used 


\section{Figure 2. Structural equation model of team social networks and quality of care for patients with cardiovascular disease ( $n=31$ primary care teams, $n=7,457$ patients).}

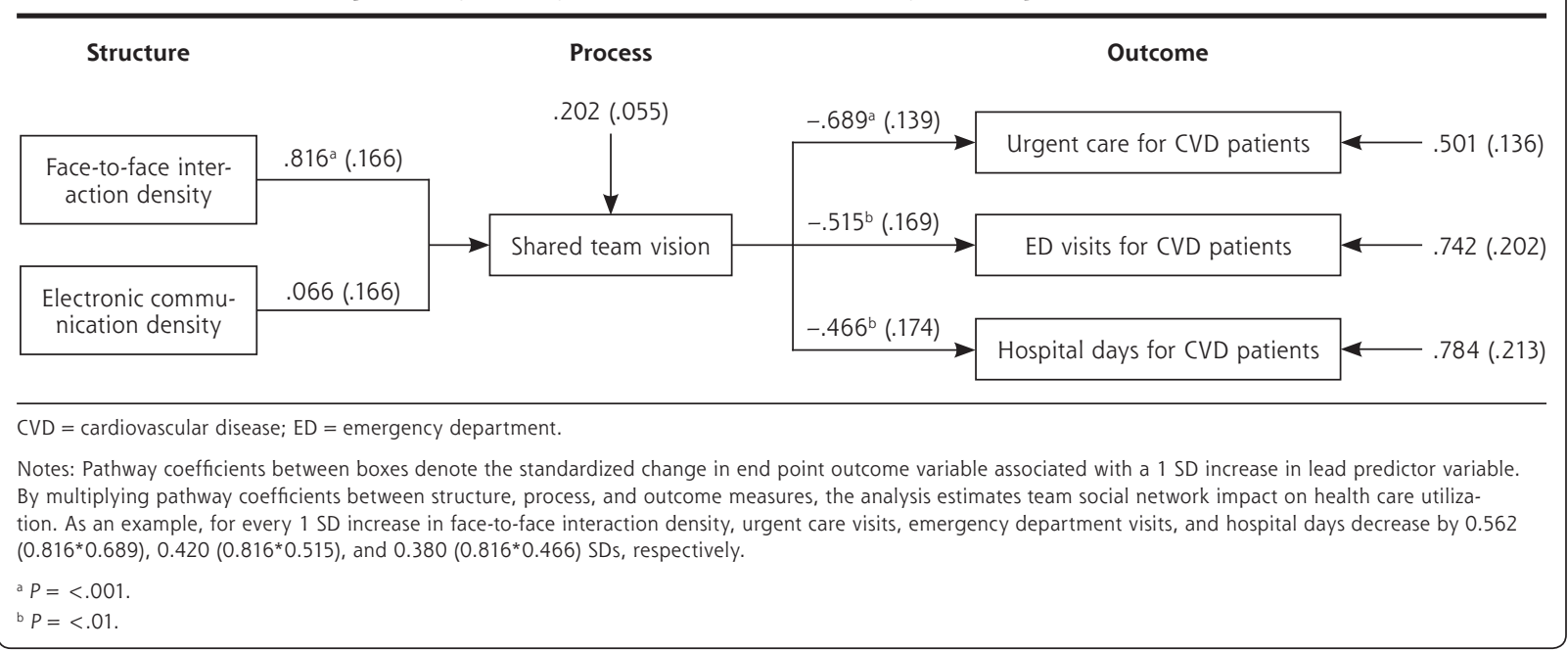

EHRs for the previous 12 years, dense EHR communication patterns not supplemented by dense face-to-face interactions were associated with less effectively controlled cholesterol levels and more emergency department visits for the team's patient panels.

Team shared vision about goals and commitments mediated the connection between team social network structures and patient outcomes. In other words, dense daily team interactions with all team members, notably, face-to-face connections, contributed to the development of shared team vision on the team's objectives and expectations, which was linked to better quality of cardiovascular disease care. Our results indicate that neither individual professional excellence nor electronic health records solutions alone could produce desired improvements in quality of care. ${ }^{4}$

Through shared vision, team social network structures may contribute to more effective team coordination (ie, management of interdependent but distinct activities involved in care provision) which is closely linked with patient outcomes. ${ }^{34-36}$ Furthermore, multiple daily interactions in teams may foster the development of trust among team members performing distinct roles, ${ }^{37}$ as well as promote energy and emotional engagement, which are essential for coordination ${ }^{38}$ and thus for patient outcomes. Cast in this light, ensuring frequent direct face-to-face interactions among all team members on a daily basis could be a cost-effective way to achieve significant improvements in cardiovascular disease care. Future studies are called for to develop team training that focuses on securing greater daily face-to-face communication among all team members.

It is important to note that this analysis cannot argue for a causal link between primary care team social networks and patient outcomes because of the cross-sectional nature of the study. Longitudinal studies are requisite to explore the causal pathways between team social connections and patient care.

Although available social network analysis literature has discussed social network effects on the adoption of health behaviors and evidence-based prevention interventions, ${ }^{39-43}$ our study shows that social network analysis could also be a valuable tool for studying the effects of team relationships on cardiovascular disease outcomes. In view of the reported $20 \%$ variance in team performance related to teamwork, ${ }^{44}$ social network analysis could offer a cost-effective way to improve patient care provision.

\section{Strengths and Limitations}

The strength of the study lies in very high response rates among eligible health professionals, complete social network information for all teams, team-level outcomes for biometric measurements of cardiovascular disease, health care use, and medical costs derived from EHRs, validated measures of team climate, and sophisticated statistical methods.

Our findings should be viewed in light of their limitations. First, our study is based on data from only 6 practices in the same geographical location, so it cannot be generalized to a broader national-level context. Second, our study did not examine the number of primary care visits by patients with cardiovascular disease. Higher utilization of primary care may provide better outcomes, but it could also point to increased understanding of patient health concerns and a more patient-centered approach to patient care, which may be indicative of better functioning teams. Third, our 
study focused only on the effects of communication network structures on patient outcomes and did not look at how other team structures (eg, use of patient registries, previsit preparation in teams) contribute to cardiovascular disease care. Fourth, our investigation also did not explore why different team members choose different modes of communication (ie, face-toface vs EHR) to discuss patient care. It is possible that the preferred mode of communication (ie, face to face vs EHR) depends on the team member's job title or the geographical layout of the clinic. Future studies may wish to explore these areas further.

Teams with dense daily face-to-face and EHR interactions among all team members who develop shared team vision are better positioned to deliver higher quality cardiovascular disease care at a lower cost.

\section{To read or post commentaries in response to this article, see it} online at http://www.annfammed.org/content/13/2/139.

Key words: patient care team; patient outcome assessment; social networks; primary health care; cardiovascular diseases; emergency departments; hospital days; face-to-face communication; team vision; electronic health records

Submitted June 9, 2014; submitted, revised, November 17, 2014; accepted December 5, 2014.

Funding support: Dr Mundt received support from the National Institute on Alcohol Abuse and Alcoholism (NIAAA), grant K01AA018410-04 for the design and conduct of the study.

Disclaimer: NIAAA had no role in the design and conduct of the study; collection, management, analysis, or interpretation of the data; preparation, review, or approval of the manuscript; or decision to submit the manuscript for publication.

Author contributions: Dr Mundt, the principal investigator, had full access to all of the data in the study and takes responsibility for the integrity of the data and the accuracy of the data analysis. Study concept and design were provided by Mundt, Gilchrist, Fleming, Zakletskaia, Tuan, Beasley. Acquisition and analysis or interpretation of data were provided by Mundt, Tuan, Zakletskaia. Drafting of the manuscript was done by Mundt, Gilchrist, Fleming, Zakletskaia, Tuan, Beasley. All authors contributed to critical revision of the manuscript for important intellectual content.

\section{References}

1. Roger VL, Go AS, Lloyd-Jones DM, et al; American Heart Association Statistics Committee and Stroke Statistics Subcommittee. Heart disease and stroke statistics-2012 update: a report from the American Heart Association. Circulation. 2012;125(1):e2-e220.

2. Smith M. Best Care at Lower Cost: The Path to Continuously Learning Health Care in America. Washington, DC: Institute of Medicine; 2013.

3. Smith M, Halvorson G, Kaplan G. What's needed is a health care system that learns: recommendations from an IOM report. JAMA. 2012;308(16):1637-1638.

4. Finley EP, Pugh JA, Lanham HJ, et al. Relationship quality and patient-assessed quality of care in VA primary care clinics: development and validation of the work relationships scale. Ann Fam Med. 2013;11(6):543-549.
5. Noël PH, Lanham HJ, Palmer RF, Leykum LK, Parchman ML. The importance of relational coordination and reciprocal learning for chronic illness care within primary care teams. Health Care Manage Rev. 2013;38(1):20-28.

6. Sinsky CA, Willard-Grace R, Schutzbank AM, Sinsky TA, Margolius D, Bodenheimer T. In search of joy in practice: a report of 23 high-functioning primary care practices. Ann Fam Med. 2013;11(3): 272-278.

7. Goñi S. An analysis of the effectiveness of Spanish primary health care teams. Health Policy. 1999;48(2):107-117.

8. Stevenson K, Baker R, Farooqi A, Sorrie R, Khunti K. Features of primary health care teams associated with successful quality improvement of diabetes care: a qualitative study. Fam Pract. 2001; $18(1): 21-26$

9. Roblin DW, Howard DH, Junling Ren, Becker ER. An evaluation of the influence of primary care team functioning on the health of Medicare beneficiaries. Med Care Res Rev. 2011;68(2):177-201.

10. Safran DG, Miller W, Beckman H. Organizational dimensions of relationship-centered care. Theory, evidence, and practice. J Gen Intern Med. 2006;21(Suppl 1):S9-S15.

11. Crabtree BF, Nutting PA, Miller WL, Stange KC, Stewart EE, Jaen CR. Summary of the National Demonstration Project and recommendations for the patient-centered medical home. Ann Fam Med. 2010; 8(Suppl 1):S80-S90; S92.

12. Brazil K, Wakefield DB, Cloutier MM, Tennen H, Hall CB. Organizational culture predicts job satisfaction and perceived clinical effectiveness in pediatric primary care practices. Health Care Manage Rev. 2010;35(4):365-371.

13. Walsh JM, McDonald KM, Shojania KG, et al. Quality improvement strategies for hypertension management: a systematic review. Med Care. 2006;44(7):646-657.

14. Carter BL, Rogers M, Daly J, Zheng SM, James PA. The potency of team-based care interventions for hypertension: a meta-analysis. Arch Intern Med. 2009;169(19):1748-1755.

15. Cardiovascular Disease Prevention. Team-based care to improve blood pressure control. http://www.thecommunityguide.org/cvd// RRteambasedcare.html. Updated Jun 16, 2014.

16. Bogden PE, Abbott RD, Williamson P, Onopa JK, Koontz LM. Comparing standard care with a physician and pharmacist team approach for uncontrolled hypertension. J Gen Intern Med. 1998; 13(11):740-745.

17. Borenstein JE, Graber G, Saltiel E, et al. Physician-pharmacist comanagement of hypertension: a randomized, comparative trial. Pharmacotherapy. 2003;23(2):209-216.

18. Erickson SR, Slaughter R, Halapy H. Pharmacists' ability to influence outcomes of hypertension therapy. Pharmacotherapy. 1997; 17(1):140-147.

19. Campbell SM, Hann M, Hacker J, et al. Identifying predictors of high quality care in English general practice: observational study. BMJ. 2001;323(7316):784-787.

20. Hess DR, Tokarczyk A, O'Malley M, Gavaghan S, Sullivan J, Schmidt $U$. The value of adding a verbal report to written handoffs on early readmission following prolonged respiratory failure. Chest. 2010; 138(6):1475-1479.

21. Valente TW. Social network thresholds in the diffusion of innovations. Soc Networks. 1996;18(1):69-89.

22. Borgatti SP, Halgin DS. On network theory. Organ Sci. 2011;22(5): 1168-1181.

23. Freeman LC. Centrality in social networks conceptual clarification. Soc Networks. 1979;1(3):215-239.

24. Anderson NR, West MA. Measuring climate for work group innovation: development and validation of the team climate inventory. J Organ Behav. 1998;19(3):235-258. 
25. Beckers Hospital Review. Average cost per inpatient day across 50 states in 2010. http://www.beckershospitalreview.com/lists/ average-cost-per-inpatient-day-across-50-states-in-2010.html. Accessed May 6, 2014.

26. Agency for Healthcare Research and Quality. Expenses for a Hospital Emergency Room Visit, 2003. http://meps.ahrq.gov/mepsweb/ data_files/publications/st111/stat111.pdf. Accessed May 6, 2014.

27. Weinick RM, Bristol SJ, DesRoches CM. Urgent care centers in the U.S.: findings from a national survey. BMC Health Serv Res. 2009;9:79.

28. Charlson ME, Pompei P, Ales KL, MacKenzie CR. A new method of classifying prognostic comorbidity in longitudinal studies: development and validation. J Chronic Dis. 1987;40(5):373-383.

29. Breslow NE, Clayton DG. Approximate inference in generalized linear mixed models. J Am Stat Assoc. 1993;88(421):9-25.

30. Cameron AC, Trivedi PK. Regression-based tests for overdispersion in the Poisson model. J Econom. 1990;46(3):347-364.

31. Asparouhov T, Muthen B. Exploratory structural equation modeling. Struct Equ Modeling. 2009;16(3):397-438.

32. Borgatti SP, Everett MG, Freeman LC. Ucinet for Windows: Software for Social Network Analysis. Harvard, MA: Analytic Technologies; 2002.

33. National Center for Health Workforce Analysis (US). The US Health Workforce Chartbook. Rockville, Md: US Dept of Health and Human Services, Health Resources and Services Administration Bureau of Health Professions, National Center for Health Workforce Analysis; 2013.

34. Leonard M, Graham S, Bonacum D. The human factor: the critical importance of effective teamwork and communication in providing safe care. Qual Saf Health Care. 2004;13(Suppl 1):i85-i90.
35. Gittell JH, Godfrey M, Thistlethwaite J. Interprofessional collaborative practice and relational coordination: improving healthcare through relationships. J Interprof Care. 2013;27(3):210-213.

36. Havens DS, Vasey J, Gittell JH, Lin WT. Relational coordination among nurses and other providers: impact on the quality of patient care. J Nurs Manag. 2010;18(8):926-937.

37. Baker DP, Day R, Salas E. Teamwork as an essential component of high-reliability organizations. Health Serv Res. 2006;41(4 Pt 2): 1576-1598.

38. Quinn RW, Dutton JE. Coordination as energy-in-conversation. Acad Manage Rev. 2005;30(1):36-57.

39. Ennett ST, Bauman KE. Peer group structure and adolescent cigarette smoking: a social network analysis. J Health Soc Behav. 1993; 34(3):226-236.

40. Alexander C, Piazza M, Mekos D, Valente T. Peers, schools, and adolescent cigarette smoking. J Adolesc Health. 2001;29(1):22-30.

41. Valente TW, Watkins SC, Jato MN, van der Straten A, Tsitsol LP. Social network associations with contraceptive use among Cameroonian women in voluntary associations. Soc Sci Med. 1997;45(5): 677-687.

42. Rogers EM. Diffusion of Innovations. 5th ed. New York, NY: Free Press; 2003.

43. Valente TW, Chou CP, Pentz MA. Community coalitions as a system: effects of network change on adoption of evidence-based substance abuse prevention. Am J Public Health. 2007;97(5):880-886.

44. Salas E, Cooke NJ, Rosen MA. On teams, teamwork, and team performance: discoveries and developments. Hum Factors. 2008;50(3): 540-547. 